\title{
The ecological techniques and materials in artistic graphic art
}

\author{
Katarzyna Winczek ${ }^{1, *}$, and Jerzy Winczek ${ }^{2}$ \\ ${ }^{1}$ Jan Długosz University, Arts Faculty, 42-200 Czestochowa, Poland \\ ${ }^{2}$ Czestochowa University of Technology, Faculty of Mechanical Engineering and Computer Science, \\ 42-201 Czestochowa, Poland
}

\begin{abstract}
In the paper, against the background of art and ecology associations, formerly and today, modern ecological techniques and materials used in artistic printmaking have been presented. The considerations were related to the culture of past centuries and searching for the threads of ecological thought in philosophy, religion or art. The development of ecological thinking in European art is traced from the Middle Ages to modern times. The trends, concepts and methods of environmental graphics are characterized in the context of development and research of these methods in the world and in Poland. The basic techniques of ecological intaglio (etching, soft varnish, aquatint, chipping, photopolymer techniques and electrolytic etching) are discussed. Alternative materials and procedures were proposed based on literature and authors' own research. The advantages and benefits of using these techniques in ecological and workshop aspects were analyzed.
\end{abstract}

\section{Introduction}

The term "ecology" is very broad and its meaning is used both in the context of biological sciences and in a vast area not related to the fields of science. In the text below, the authors refer to the meaning of the coexistence of man, the artist and his actions in the space of the work environment and the natural environment.

„For the purposes of our considerations, we adopt a general definition of the concept of ecological culture as a set of values related to the new, still developing paradigm of thinking about a man, his place and role in the world, as well as the obligations that govern his reference to other people and other life forms" [1].

\section{Ecology and art over the centuries}

Considering various aspects of the relationship between art and ecology, one cannot fail to refer to the culture of past centuries and to find the threads of ecological thought in philosophy, religion or art. The term "ecology" itself was formulated by a German biologist in the nineteenth century, whereas the common pro-ecological movements, also expressed

\footnotetext{
* Corresponding author: katarzynawinczek@gmail.com
} 
in art, date back to the beginning of the 1960s. The ideas expressed by this movement coincide with the views dating back to antiquity and the Middle Ages.

Ecological thought in European art has its sources, among others in the religious views of the saints of the Middle Ages, pointing to a strong bond connecting man, the world around him and God. This thought can be found in the texts of Saint Hildegard of Bingen, a Benedictine nun of the $11^{\text {th }} / 12^{\text {th }}$ century. Mystical holy books represent the created world of micro- and macrocosm, as a work full of harmony and perfection. Contemporary ecological views also point to the ideas and the figure of Saint Francis of Assisi, living at the turn of the XII/XIII century, whose writings and actions expressed the idea of living in harmony with the rhythm and harmony of nature, the "sense of the human relationship with the world, with an animate and inanimate nature attitude of humbleness and admiration for the power and beauty of nature as a divine work and a precious gift" [1].

Ecological art, just like sacred art, distinguishes, above all, the type of artistic message. Common areas between art and ecology can relate to forms of expression, subject to present - the idea. The medium used (the material of creative expression) may be an ecological choice of the artist, e.g. with non-toxic properties that do not contain harmful ingredients. These include natural materials, such as wood, stone and clay. Most of the traditional drawing and painting materials, where the substrate is paper and the solvent of some of them is water, such as: graphite, ink, coal, pastel, watercolor, tempera, gouache, acrylic paints, ecoolins or drawing inks, can be classified as harmless. It is different with other drawing and painting materials: oil paints, varnishes, solvents, aerosol fixations for fixing the drawing surface and aerosol adhesives. Because some of them are flammable products and have an irritant effect on the respiratory tract, their use requires ensuring proper working conditions in the room. The contemporary artist also uses many non-standard materials intended for other purposes than creativity, e.g. plastics, aerosol paints or other coatings used in civil engineering and industry. It results from the widening of the area of impact of visual arts, for example in the public space, the exhibition of large format works and performed on various substrates. In particular, young painters and street artists usually work with spray paint.

Commonly known examples of art and ecology are earth art, a trend in art created in the USA based on the interest in new philosophical and aesthetic trends, which is an expression of the emerging new artistic movement (e.g. R. Smithson, M. Heizer, D. Oppenheim, Christo). The earth art had its artists in Europe also (e.g. R. Long, ). In Poland, a certain form of this type of activity was dealt with by min. J. Kozakiewicz and J. Koziara.

\section{Trends, concepts and methods in ecological printmaking}

Of all the arts, the graphic artist's workshop is most dependent on the technological aspect of creative activities. Due to the specificity of graphic techniques, previously used both in reproductive graphics and now in graphic design, the artist's work environment can become a source of harmful factors. Below is an alternative to traditional graphic workshop, based on the use of harmless methods and materials. It can be successfully used both in professional individual practice and in educational activities with various groups of participants.

Techniques for gravure printing have been known in Europe since around the 16-th century. The conventional graphic workshop is based on the tradition of using varnishes, fatty paints and metal-pickling agents: iron chloride and mainly nitric acid. This technology is widely used in many graphic, art and school workshops. The so-called non-toxic techniques, based on acrylic technology, began to be used in the 90's in Canada, USA, Denmark and Finland. The first theoretical studies also come from these years. It is worth mentioning above all the works Behr [2-5]. Semenoff [6, 7] Reed [8], Hoskins [9], 
Kiekeben [10], Green [11, 12], Howard [13, 14] and Bǿegh [15]. Since then, in many European countries (including Norway, Belgium, the Netherlands, Spain, France, Germany and Great Britain), intensive work has been underway to develop and improve these techniques. In some universities there are studies with the specialty of non-toxic printmaking (in Canada: Canadian School of Non-Toxic Printmaking in Alberta; in the United States at least 25 universities including the University of Maine, Dayton, Lander, The Rochester Institute of Technology and at many state universities. In Europe, non-toxic graphic work rooms operate among others in Denmark, Great Britain, Spain and Ireland. A well-known center promoting new non-toxic technologies is the Edinburgh Printmakers in Scotland [16].

Electroplating has been known for over 200 years [17], but the principles of electrolytic etching (electrogravure) have been better understood in the $19^{\text {th }}$ century. In 1840 , T. Spencer and J. Wilson described and patented an electrolytic process called electroetching [18]. Their work "Engraving Metals by Voltaic Electricity" has been published in the USA in 1859. The description of this process was also taken up by J. Waterhouse and R.S. Chattock, who developed a technical specification for the use of artists. The electrolytic method was also used to reproduce photographs. P. Pretsch invented "photogalvanography", used in England for the first photographic reproduction prints. Also in France in the 19-th century reproductions of art works were published this way. In the twentieth century, electro-etching became known and popular among graphic artists, especially in the USA, so many graphic centers were created to popularize this method. In Canada, the well-known authors of the description of the electrolytic technique for artists are N. Semenoff and Ch. Christos [6].

The main directions of artistic and technological research should be mentioned:

- techniques of preparing matrices, including materials for grounding and etching,

- cleaning agents matrices and tools with low harmfulness to the artist's health and to the environment,

- printing inks with a lower content or completely free of toxic components.

In Poland, in the university environment, research on the application of non-toxic graphic techniques (electrolytic etching tests, etching in iron chloride) was initiated, among others, at the Art Institute of Jan Długosz University in Częstochowa in the middle of the past decade. Among other academic centers in Poland, the teachers-artists of the Academies of Fine Arts in Gdańsk and Katowice became interested in the issues of non-toxic metal techniques.

\section{Ecological techniques for intaglio printing}

Ecological intaglio printing techniques are closely related to the preparation methods of matrices and the used materials. In so-called metal techniques, the matrix used for printing graphics is usually made of zinc and copper sheets. The preparation of such a sheet starts with coating its surface with a resistant coat to the use of etching agents. For this purpose, varnish or rosin is used. Varnish is made on the base of wax, rosin and tar substances. The rosin itself is used as a powder applied to the surface of the sheet. Applying coatings from a solid varnish or rosin requires heating the sheet, during which harmful toxic or carcinogenic fumes are emitted. Instead of traditional varnish based on wax, rosin and tar substances, acrylic primers are used. These types of soil can be successfully used in techniques such as etching, aquatint or soft varnish. After the soil dries, a drawing is made on the matrix, revealing the places of the matrix to be etched. After etching, the soil from the matrix surface is removed with a harmless liquid. Tools used to prepare the matrix are cleaned with warm water and detergents (possibly with soap), not with petrol or kerosene based solvents, as is the case in classical techniques. In the case of soft varnish, 
it is also possible to obtain effects using the reflection of traces of structures such as templates, fabrics, fibers, natural forms (leaves, dead insects, etc.). In the technique of a slow-drying soft varnish, the soil used is a mixture of wax, rosin, lithographic paint and fat (e.g. lard), and it is washed with vegetable oil. In the fat painting technique, the drawing is made with a fatty substance, which may be oil, butter, lipstick, vaseline, oil paint, etc. The matrix is then sprayed with a hard acrylic primer, cured, and then a "splinter" drawing is recovered, removing greasy areas. The reverse fat technique consists in drawing with a fat pencil on the aquatint covering the plate.

Brand new photopolymer techniques are completely new methods of creating the matrix. They consist in UV exposure of a matrix covered with a photopolymer foil, and then developing and hardening the image.

After drawing on the matrix, it is subjected to etching. In classical techniques, dilute nitric acid (zinc, copper) and hydrochloric acid (copper) are used. Instead of acids, one can use iron chloride or digestive mixtures, such as Saline Sulphate Etch, Bordeaux Etch or Edinburgh Etch. The electrolytic method can be used to etch the matrices. The electrolytic method can be used to etch matrices prepared with almost all the abovementioned techniques (etching, aquatint, soft ground). The use of electrolytes prepared on the basis of copper sulphate or zinc sulfate is safer than the use of hydrochloric acid and nitric acid.

\section{Materials}

Along with technological progress and the development of knowledge in the field of materials science and knowledge of the aforementioned processes, the search for solutions, methods, techniques and substances reducing the risk of harmfulness or eliminating threats has begun. A list of selected measures used in traditional graphic techniques with threats resulting from their use and alternative solutions is provided in Table 1. Some of them (eg. acrylic primers) are described above, describing techniques for preparing etching matrices.

\subsection{Etching}

In place of acids (nitrogen, hydrochloric, Dutch bath), it is postulated to use iron chloride or digestive mixtures, such as Saline Sulphate Etch, Bordeaux Etch or Edinburgh Etch.

Saline Sulphate Etch is a substance that arises from mixing copper sulphate and table salt in water and can be used for pickling zinc, aluminum and mild steel. Listed below is e method for preparing a sulfate solution [19]:

1) prepare a plastic container to make up the solution,

2) put on gloves, a dust mask and safety goggles (a protective mask is necessary to protect the airways against inhalation of sulphate and salt particles during solution preparation),

3) carefully pour into the container equal amounts, for example $100 \mathrm{~g}$ copper sulphate and table salt, you can mix these substances, but it is not necessary,

4) then slowly pour $500 \mathrm{ml}$ of hot water, stirring the solution with, for example, a stick, a wooden or plastic spoon. A thick solution of green color is formed,

5) add another $500 \mathrm{ml}$ to 1 liter of warm water with continuous mixing. The crystals should dissolve within 5 to 15 minutes of mixing, depending on the amount and temperature of the water, forming a dark green liquid.

Sample amount of 12 liters bath ingredients: $1 \mathrm{~kg}$ of copper sulphate, $1 \mathrm{~kg}$ of sodium chloride, 5 liters of hot water, 5 liters of warm water. 
Table 1. Comparison of threats and traditional methods with less harmful techniques.

\begin{tabular}{|c|c|c|c|}
\hline Action & $\begin{array}{c}\text { Traditional } \\
\text { methods }\end{array}$ & $\begin{array}{c}\text { Main sources and } \\
\text { health risks }\end{array}$ & $\begin{array}{c}\text { Alternative methods and } \\
\text { agents }\end{array}$ \\
\hline $\begin{array}{c}\text { Etching of } \\
\text { copper } \\
\text { matrices }\end{array}$ & $\begin{array}{c}\text { Acids: nitric, } \\
\text { hydrochloric; } \\
\text { Dutch bath }\end{array}$ & $\begin{array}{c}\text { Nitrogen dioxide, } \\
\text { chlorine, irritation of the } \\
\text { eyes, lungs, nasal and } \\
\text { throat mucosa, skin. }\end{array}$ & $\begin{array}{c}\text { Electrolytic etching, } \\
\text { Edinburgh Etch. }\end{array}$ \\
\hline $\begin{array}{c}\text { Etching of } \\
\text { zinc matrices }\end{array}$ & Nitric acid & $\begin{array}{c}\text { Irritation of eyes, lungs, } \\
\text { nasal and throat mucosa, } \\
\text { skin. }\end{array}$ & $\begin{array}{c}\text { Electrolytic etching, Saline } \\
\text { Sulphate Etch, Bordeaux Etch. }\end{array}$ \\
\hline $\begin{array}{c}\text { Hard and soft } \\
\text { varnish }\end{array}$ & $\begin{array}{c}\text { Hard and } \\
\text { (including } \\
\text { bitumen, } \\
\text { rosin, } \\
\text { turpentine). }\end{array}$ & $\begin{array}{c}\text { Toxic or carcinogenic } \\
\text { fumes during heating, } \\
\text { irritation of mucous } \\
\text { membranes, nausea, } \\
\text { headaches, depression of } \\
\text { the central nervous } \\
\text { system. }\end{array}$ & $\begin{array}{c}\text { Acrylic hard and liquid } \\
\text { acrylic; soft oil-based primer } \\
\text { (removed with water and } \\
\text { baking soda, food oil, water } \\
\text { and soap). }\end{array}$ \\
\hline $\begin{array}{c}\text { Aquatint } \\
\text { powdered } \\
\text { pine rosin }\end{array}$ & $\begin{array}{c}\text { Toxic fumes of baked } \\
\text { rosin, allergy to rosin } \\
\text { dust. }\end{array}$ & $\begin{array}{c}\text { Acrylic aquatint, fractint } \\
\text { technique in electrolytic } \\
\text { etching. }\end{array}$ \\
\hline $\begin{array}{c}\text { Paints and } \\
\text { protective } \\
\text { lacquers }\end{array}$ & $\begin{array}{c}\text { Oil-based } \\
\text { printing inks, } \\
\text { lacquers based } \\
\text { on methyl } \\
\text { alcohol. }\end{array}$ & $\begin{array}{c}\text { Headaches, skin and eye } \\
\text { irritation. }\end{array}$ & $\begin{array}{c}\text { Water printing inks, acrylic } \\
\text { paints, lacquer-dissolved in } \\
\text { alcohol. Foil to protect the } \\
\text { surface. }\end{array}$ \\
\hline $\begin{array}{c}\text { Cleaning of } \\
\text { matrices and } \\
\text { tools from } \\
\text { varnish, paint } \\
\text { (oil-based), } \\
\text { lacquer. }\end{array}$ & $\begin{array}{c}\text { Turpentine, } \\
\text { kerosene, } \\
\text { gasoline. }\end{array}$ & $\begin{array}{c}\text { Irritation of the mucous } \\
\text { membranes, depression } \\
\text { of the central nervous } \\
\text { system, skin damage, } \\
\text { suspicion of kidney } \\
\text { damage. }\end{array}$ & $\begin{array}{c}\text { Ethyl alcohol for cleaning } \\
\text { lacquer, vegetable oil for } \\
\text { cleaning oil-based inks, } \\
\text { household detergents, soapy } \\
\text { water. }\end{array}$ \\
\hline
\end{tabular}

Edinburgh Etch is a copper etching agent that uses iron chloride and citrate. During the reaction of copper compounds with citric acid, a small amount of hydrochloric acid may be released. Citric acid is well soluble in water and does not pose a threat in the form of vapors. Edinburgh Etch is prepared in proportions: $80 \%$ by volume is $40 \%$ saturated iron chloride, and $20 \%$ by volume solution of anhydrous citric acid dissolved in water in proportions of 3 portions of water per 1 portion of citric acid [19]. Examples of amounts of bath components: 6 liters of $40 \%$ iron chloride, 1.2 liters of a solution consisting of $900 \mathrm{ml}$ of water and $300 \mathrm{ml}$ of citric acid, it should be assumed that $300 \mathrm{ml}$ of citric acid corresponds to a mass of $300 \mathrm{~g}$ of powder.

Bordeaux Etch is used for etching zinc and aluminum. It is made of copper sulphate, table salt and a weak acidifying agent with a $\mathrm{pH}$ of 2.5-4.5, which makes the solution much safer to use than acids. Satisfactory digestion results are obtained by using the following recipe [20]: $1 \mathrm{~kg}$ of copper sulphate $\left(\mathrm{CuSO}_{4}\right), 250 \mathrm{~g}$ of table salt $(\mathrm{NaCl}$ sodium chloride), $25 \mathrm{~g}$ of sodium hydrogen sulphate $\left(\mathrm{NaHSO}_{4}\right)$ and water $\left(\mathrm{H}_{2} \mathrm{O}\right)-10-201$ in depending on the concentration of the bath.

\subsection{Electrolytic etching}

The electric current parameters used do not pose a significant threat (voltage up to $10 \mathrm{~V}$ at an intensity current of up to $10 \mathrm{~A}$ ). Below are exemplary amounts of copper sulphate 
to be dissolved in 1 liter of demineralized water to make electrolytes for etching metal matrices:

a) cooper: weak - $160 \mathrm{~g}$, medium - $200 \mathrm{~g}$, strong - $250 \mathrm{~g}$,

b) zinc: weak - $160 \mathrm{~g}$, medium - $300 \mathrm{~g}$, strong - $500 \mathrm{~g}$,

c) steel: weak - $200 \mathrm{~g}$, strong - $500 \mathrm{~g}$.

Do not experimentally mix the electrolyte with the above-described etching solutions (Saline Sulphate, Edinburgh or Bordeaux), because then during the electrolysis very harmful substances may be released.

\subsection{Print inks, paints}

The process of printing graphics is a stage that apparently contains relatively the least threats to the health of the artist and the environment. The printing inks consist of coloring substances, binders, solvents and auxiliary substances [21]. Coloring substances are organic and inorganic pigments of organic and inorganic origin as well as acid, alkaline and other dyes, whereas binders are created on the basis of oil varnishes and resins dissolved in various types of solvents [21]. Inorganic pigments contain metal compounds such as lead, zinc, aluminum, iron, chromium, titanium and sulfur compounds [21]. For print inks, zinc white is used, which is a direct threat only in the form of powder, it is considered harmful to the environment. When applying ink on an intaglio print metal matrix, it is often heated, then different chemical compounds are released, which in the vapors are a threat to the artist's health, such as, for example, alcohols, dichlorethanes, xylenes, acetates, chloroform or toluene. The list of all compounds is long and counts dozens of items [22]. Although the amount of these compounds emitted during the artist's work is small, but with long-term work, the accumulation of these compounds in a workshop environment may be harmful. That is why more and more attempts are being made to use water and acrylic paints.

\section{Conclusions}

The use of non-toxic techniques and media in the graphic arts is mainly supported by the ecological aspect - the tradition of non-toxic techniques is characterized by the accomplishments of graphic environments in the countries of Western Europe and in the USA and Canada. In these countries, ecological consciousness of societies and care for the natural environment are at a high level. The advantage of using non-toxic methods of metal etching is the safe use of other substances that have a low harmful effect on the human body, as well as in the form of waste on the natural environment. One cannot ignore the educational aspect related to the dissemination of new, safe methods of work among students and graphic artists.

\section{References}

1. F. Chmielowski, The presence of ecological thinking in the visual arts (in Ed. M. Gołaszewska: Knowledge and experience. Essays on the aesthetics of ecology, Universitas, Kraków, 2000)

2. O.M. Behr, M.R. Behr, Chemtech 21, 4, 210-215 (1991)

3. M. Behr, Leonardo 26, 1, 53 (1993)

4. M. Behr, Printmaking Today 3, 1, 8 (1994)

5. M. Behr, Printmaking Today 4, 4, 24-25 (1995) 
6. N. Semenoff, C. Christos, Leonardo 24, 389--394 (1991)

7. N. Semenoff, L. Bader, Leonardo 31, 133-138 (1998)

8. S. Reed, Artists Newsletter 4, 38-39 (1994)

9. S. Hoskins, R. Pearce, Printmaking Today 4, 2, 24-25 (1995)

10. F. Kiekeben, Printmaking Today 6, 3, 26-27 (1997)

11. C. Green, Printmaking Today 7, 1, 25-27 (1998)

12. C. Green, Handbook on some new methods for safe intaglio etching and metal plate printmaking (Ecotech Design, Sheffield, 2004)

13. K. Howard, Non - Toxic Intaglio Printmaking (Printmaking Resources, Alberta, 1998)

14. K. Howard, The Contemporary Printmaker (Write-Cross Press, New York, 2003)

15. H. Bǿegh, Handbook of Non-Toxic Intaglio (Forlaget Boegh, Dania, 2007)

16. http://www.nontoxicprint.com/printmakingresources.htm

17. J. Socha, J.A. Weber, Inżynieria Powierzchni 1, 3-10 (2004)

18. T. Spencer, J. Wilson, Certain improvements in the process of engraving on metals by means of voltaic electricity, Patent for invention: A.D. 1840.- ${ }^{\circ} 8656$.

19. http://nontoxicprint.com/etchzincsteelaluminum.htm

20. http://printmakerscorner.com/mordants.html

21. S. Jakucewicz, Print inks (Michael Huber Polska, Wrocław, 2001)

22. J. Kowalska, I. Makniashvili, M. Pośniak, Bezpieczeństwo pracy 9, 20-23 (2006) 